Florida International University FIU Digital Commons

\title{
Public Infrastructure, Input Efficiency and Productivity Growth in the Canadian Food Processing Industry
}

Jeffrey I. Bernstein

Department of Economics, Florida International University, bernstej@fiu.edu

Theofanis P. Mamuneas

Department of Economics, University of Cyprus,

Follow this and additional works at: https://digitalcommons.fiu.edu/economics_wps

\section{Recommended Citation}

Bernstein, Jeffrey I. and Mamuneas, Theofanis P., "Public Infrastructure, Input Efficiency and Productivity Growth in the Canadian Food Processing Industry" (2007). Economics Research Working Paper Series. 50.

https://digitalcommons.fiu.edu/economics_wps/50 


\title{
Public Infrastructure, Input Efficiency and Productivity Growth in the Canadian Food Processing Industry*
}

\author{
Jeffrey I. Bernstein ${ }^{\dagger} \quad$ Theofanis P. Mamuneas ${ }^{\ddagger}$
}

December 2006

\begin{abstract}
Canadian food processing is an important manufacturing industry, accounting for 13 percent of shipments. By its nature food processing depends on infrastructure capital. Our objective is to estimate infrastructure's effects on input requirements, cost and productivity. The increase in capital and decrease in materials were respectively 2.5 and 3 times greater than the -0.07 infrastructure elasticity of labor. Infrastructure investment was cost-reducing by inducing reductions in employment and intermediate inputs. A 1 percent increase caused cost to decline by 0.16 percent. Infrastructure capital was a major contributor to productivity, annually contributing 0.5 percentage points. This was nearly double TFP growth.
\end{abstract}

JEL No. D24, L66

Keywords: Food Processing, Infrastructure Capital, Productivity Growth

\footnotetext{
${ }^{*}$ The authors would like to thank Sean Cahill for research assistance in developing the dataset used in this paper.

${ }^{\dagger}$ Department of Economics, Florida International University, Miami, Florida 33199 USA, and NBER (e-mail: jeffrey.bernstein@fiu.edu

${ }^{\ddagger}$ Department of Economics, University of Cyprus, P. O. Box 20537, CY-1678 Nicosia, Cyprus (e-mail: tmamuneas@ucy.ac.cy).
} 


\section{INTRODUCTION}

The food processing industry is one of the most important manufacturing industries in Canada. Over the past decade food processors' share of manufacturing value of total shipments has averaged 13 percent, which is second to the transportation equipment industry. Over the same period, employment in food processing has exceeded all other manufacturing industries, with an average share of 12 per cent of manufacturing employment (see figures 1 and 2 in the Appendix). ${ }^{1}$ By its very nature, the profitability of this industry crucially depends on its timely ability to distribute its output to downstream wholesale and retail firms. Consequently, an important input in food processing production is the network of highways and railways, or in general, the level of public infrastructure capital.

Investment in public infrastructure capital (by the federal, provincial and municipal governments) accounts for about 12 per cent of all non-residential investment in Canada. Since the level of infrastructure is set by government policy, private sector firms make their production decisions subject to the given or exogenous level of infrastructure capital. This means that changes in public infrastructure capital will typically lead to changes in private sector production processes. The purpose of this paper is to measure the effect of public infrastructure provision on production techniques (in other words input requirements), the cost of production and the productivity growth of Canadian food processors.

This paper considers infrastructure investment within the context of intertemporal cost minimization, where public infrastructure capital is viewed as a government determined production input, whose effects are estimated simultaneously with other parameters characterizing the overall structure of production. In particular, a potentially important effect arising from infrastructure investment is its contribution to productivity growth. Investment in infrastructure capital reduces production cost, because inputs are more effectively transformed into outputs, which then enhances productive efficiency. Specifically productivity performance improves.

The approach adopted in this paper extends previous empirical research in the area in a number of directions (see the survey by Nadiri and Mamuneas [1996] and the references cited 
therein). The literature dealing with the measurement of the effects of public infrastructure tend to fall into one of two categories: i) production function approaches that measure the effect of public infrastructure on productivity growth, and ii) cost function approaches that measure the effect of public infrastructure on cost, input demands and productivity. The first category of studies ignore the effect of infrastructure investment on production techniques or factor requirement, while the second category of studies are typically static in nature. In addition, many cost function studies are short-run and report effects of public infrastructure on variable cost and variable inputs (e.g. labour), while ignoring potentially important effects on the demand for capital. The model under consideration is an extension of Bernstein, Mamuneas and Pashardes [2004], where production decisions regarding both non-durable, and capital input requirements involve intertemporal considerations. Thus the model is dynamic, and results in nonlinear investment and input demand equations. Moreover, since the benefits of infrastructure investment extend into future time periods, a proper evaluation of the contribution of infrastructure capital involves expectations of future prices. As a consequence, price expectations are a potentially important element of the evaluation process. In this paper, in contrast to previous research, price expectation generating processes are jointly estimated with the production structure.

The paper is organized in the following manner. Section 2 develops the theoretical model providing the framework to estimate the effects of public infrastructure capital. Section 3 contains the discussion on the empirical specification, the regression results, and hypothesis tests on model specification. Section 4 addresses the estimated infrastructure elasticities of factor demand, and production cost. Section 5 develops and decomposes total factor productivity (TFP) growth rates, and determines the contribution of infrastructure capital. The last section concludes the paper.

\section{PRODUCTION AND PUBLIC INFRASTRUCTURE}

This section develops a model incorporating public infrastructure capital into a production process. This framework forms the basis for the estimation model in the following 
section. To begin, consider a production function written as:

$$
y_{t}=F\left(v_{1 t-1}+h_{1}\left(v_{1 t}-v_{1 t-1}\right), \ldots, v_{n t-1}+h_{n}\left(v_{n t}-v_{n t-1}\right), G_{t}, t\right)
$$

where $y_{t}$ is output quantity in period $t, F$ is the production function, $v_{i t}$ is the $i$ th input quantity in period $t, G_{t}$ is an $l$ vector of public infrastructure capital stocks in period $t$ and $t$ also represents the exogenous disembodied technology index. ${ }^{2}$

Equation (1), through the $h_{i} i=1, \ldots, n$ parameters, provides for changes in technical efficiency levels accompanying factor additions. These parameters reflect the variations in "net" efficiency by capturing the gains from factor improvements, and the losses associated with adjustment costs. To see more clearly the role of these parameters, first consider $h_{i}=1$, for $i=1, \ldots, n$. In this is the case the marginal product of net additions of input $i$ in the current period is the same as that of existing units of the input. This equivalence is due, for example, to the increased technical efficiency of net additions being offset by adjustment costs. In other words the productive efficiency of an additional quantity equals the current efficiency level for the input, and the standard production function, $y_{t}=F\left(v_{1 t}, \ldots, v_{n t}, G_{t}, t\right)$, emerges. Next, suppose $h_{i}>1$. In this case, the marginal product of net additions of input $i$ in the current period exceeds that of existing units of the input. Accordingly, the benefits from factor improvements dominate adjustment costs incurred through incorporating new inputs into the production process. In this situation, relative to the case where $h_{i}=1$, more output is produced from a given set of input additions, and consequently factor additions are more productive than existing inputs. Lastly when $0<h_{i}<1$, the marginal product of net additions of input $i$ in the current period is lower than that of existing units of the input. Adjustment costs dominate the benefits associated with factor improvements, and as a result factor additions are less productive than existing inputs. ${ }^{3}$

The $h_{i}$ parameters represent levels of net efficiency. The possibility that efficiency parameters associated with factor improvements can be reliably estimated, or even separately identified, in an econometric sense, from parameters associated with adjustment costs is extremely tenuous. This may be a reason that adjustment cost models ignore the efficiency implications from factor improvement. One of the attractions of the current model is the 
parsimonious treatment of efficiency into a single parameter for each input. Moreover, in this model, unlike adjustment cost models, there is no fixed boundary between factors displaying efficiency gains, or losses, and factors for which efficiency growth is constrained a priori. $^{4}$

Factor accumulation is represented by the usual condition:

$$
v_{i t}=x_{i t}+\left(1-\delta_{i}\right) v_{i t-1}, i=1, \ldots, n,
$$

where $x_{i t}$ is the addition to the $i$ th input quantity in period $t$, and $0 \leq \delta_{i} \leq 1$ is the $i$ th input depreciation rate. ${ }^{5}$ Since the depreciation rates for nondurable input quantities are defined as $\delta_{i}=1$, in these cases from $(2) v_{i t}=x_{i t}{ }^{6}$

Input demands are determined from minimizing the expected present value of acquisition and hiring costs. The expected present value at time $t$ (defined as the current time period) is given by the following:

$$
\sum_{s=0}^{\infty} \sum_{i=1}^{n} a(t, t+s) q_{i t+s}^{e} x_{i t+s}
$$

where $q_{i t+s}^{e}$ is the expectation in the current period $t$ of the $i$ th factor acquisition (or hiring) price in period $t+s$, and $a(t, t+s)$ is the discount factor with $a(t, t)=1, a(t, t+1)=$ $\left(1+\rho_{t+1}\right)^{-1}$, where $\rho_{t+1}$ is the discount rate from period $t$ to period $t+1 .^{7}$ The expression in (3) is minimized subject to equation sets (1), and $(2)^{8}$ The Lagrangian for the problem is:

$$
\begin{aligned}
\mathcal{L}= & \sum_{s=0}^{\infty} a(t, t+s)\left\{\sum_{i=1}^{n} q_{i t+s}^{e}\left[v_{i t+s}-\left(1-\delta_{i}\right) v_{i t+s-1}\right]\right. \\
& \left.-\lambda_{t+s}\left[F\left(h_{1}\left(v_{1 t+s}-\mu_{1} v_{1 t+s-1}\right), \ldots, h_{n}\left(v_{n t+s}-\mu_{n} v_{n t+s-1}\right), G_{t+s}, t+s\right)-y_{t+s}\right]\right\}
\end{aligned}
$$

where $\lambda_{t+s}$ is the Lagrangian multiplier in period $t+s$, and $\mu_{i}=\left(1-h_{i}^{-1}\right)$. Differentiating (4) with respect to $v_{i t+s}$, and defining $z_{i t+s}=h_{i}\left(v_{i t+s}-\mu_{i} v_{i t+s-1}\right)$, which can be considered the $i$ th efficiency-adjusted input in period $t+s$, the first order condition for the $i$ th input in period $t+s$ is:

$$
\lambda_{t+s} \frac{\partial F}{\partial z_{i t+s}} h_{i}=w_{i t+s}^{e}+a \mu_{i} \lambda_{t+s+1} \frac{\partial F}{\partial z_{i t+s+1}} h_{i}, i=1, \ldots, n,
$$


where $w_{i t+s}^{e}=q_{t+s}^{e}-a q_{i t+s+1}^{e}\left(1-\delta_{i}\right)$, is the $i$ th factor price in period $t$, but expected in period $t+s$, and $a=a(t, t+s+1) / a(t, t+s)$ is the constant discount factor.

Evaluating (6) for the time periods from $t$ to $t+T$, solving the system recursively with $T=\infty$, and imposing the transversality condition that the shadow value of the marginal product for each factor is zero, that is $\lambda_{t+T+1} \partial F / \partial v_{i t+T+1}=0$, for $i=1, \ldots, n$, at $T=\infty$, then:

$$
\lambda_{t} \frac{\partial F}{\partial z_{i t}}=h_{i}^{-1}\left\{w_{i t}+\sum_{s=1}^{\infty} w_{i t+s}^{e}\left(a \mu_{i}\right)^{s}\right\}, i=1, \ldots, n,
$$

where $w_{i t}=q_{t}-a q_{i t+1}^{e}\left(1-\delta_{i}\right)$. From the definition of $z_{i t+s}=h_{i}\left(v_{i t+s}-\mu_{i} v_{i t+s-1}\right)$, this variable represents efficiency-adjusted quantity. Therefore equation (6) shows the intuitive result that the value of the marginal product for each efficiency-adjusted input equals its respective user cost, which is defined by the right side of (6) (call $\omega_{i t}$ the $i$ th user cost in period $t) .9$

The user cost derivation enables us to recast the problem defined by (4). in the following equivalent form:

$$
\min _{z_{i t}} \sum_{i=1}^{n} \omega_{i t} z_{i t}
$$

subject to the production function given by $y_{t}=F\left(z_{1 t}, \ldots, z_{n t}, G_{t}, t\right)$, for periods $t=0, \ldots, \infty$. The problem in (7) relates to minimizing efficiency-adjusted production costs, and leads to the first order conditions denoted by (6). The equivalency of cost minimizing problems enables us to define a cost function, which is denoted as:

$$
C\left(\omega_{1 t}, \ldots, \omega_{n t}, y_{t}, G_{t}, t\right)
$$

This function depends on user costs, (and thereby depreciation and technical efficiency parameters, expected acquisition and hiring prices), output quantity, and technology index. Moreover, by differentiating (8) with respect to the user costs, it is possible to retrieve the efficiency-adjusted factor demands according to:

$$
z_{i t}^{*}=\frac{\partial C\left(\omega_{1 t}, \ldots, \omega_{n t}, y_{t}, G_{t}, t\right)}{\partial \omega_{i t}}, i=1, \ldots, n,
$$

where the optimized value of the $i$ th efficiency-adjusted input is $z_{i t}^{*}=Z_{i}\left(\omega_{1 t}, \ldots, \omega_{n t}, y_{t}, G_{t}, t\right)$. Unfortunately, equation set (9) cannot be estimated because of the unobservability of 
efficiency-adjusted factor demands. These variables are not observable because the technical efficiency parameters are unknown. However, since $z_{i t}=h_{i}\left(v_{i t}-\mu_{i} v_{i t-1}\right)$, then evaluating this relationship at the optimized value, expression (9) can be rewritten as:

$$
v_{i t}^{*}=h_{i}^{-1} \frac{\partial C\left(\omega_{1 t}, \ldots, \omega_{n t}, y_{t}, G_{t}, t\right)}{\partial \omega_{i t}}+\mu_{i} v_{i t-1}, i=1, \ldots, n .
$$

where $v_{i t}^{*}=V_{i}\left(\omega_{1 t}, \ldots, \omega_{n t}, y_{t}, G_{t}, t\right)$ is the optimized value of the observable $i$ th factor demand. Equation set (10) shows the equilibrium conditions in terms of observable factor quantities, and forms the basis for the estimation model, which is specified in the following section.

\section{SPECIFICATION AND ESTIMATION}

This section specifies the cost function, and the price expectation generating processes for the acquisition and hiring prices required to estimate the model. The cost function, is assumed to be the symmetric generalized McFadden functional form:

$$
\begin{aligned}
c_{t} & =\left(\sum_{i=1}^{n} \beta_{i} \omega_{i t}+\frac{.5 \sum_{i=1}^{n} \sum_{j=1}^{n} \beta_{i j} \omega_{i t} \omega_{j t}}{\sum_{i=1}^{n} b_{i} \omega_{i t}}+\sum_{i=1}^{n} \beta_{i G} \omega_{i t} G_{t}+\beta_{G G} G_{t}^{2} \sum_{i=1}^{n} b_{i} \omega_{i t}\right) y_{t} \\
& +\sum_{i=1}^{n} \alpha_{i} \omega_{i t}+\alpha_{t} t \sum_{i=1}^{n} b_{i} \omega_{i t}+\alpha_{G} G_{t} \sum_{i=1}^{n} b_{i} \omega_{i t}+\alpha_{y y} y_{t}^{2} \sum_{i=1}^{n} b_{i} \omega_{i t},
\end{aligned}
$$

where the parameters are denoted by the $\alpha$ 's and $\beta$ 's. The $n \times n$ matrix formed by the $\beta_{i j}$, parameters is symmetric, and must be negative semidefinite so that the function is concave in user costs. The $b_{i}, i=1, \ldots, n$ are nonnegative constants that are not all zero for some reference time period $\tau$. For the reference time period, the cost function is homogenous of degree one in user costs if $\sum_{i=1}^{n} \beta_{i j} \omega_{i \tau}=0$, and $\sum_{i=1}^{n} b_{i} \omega_{i \tau} \neq 0$. The expression $\sum_{i=1}^{n} b_{i} \omega_{i t}$ is an index of input prices, and the constants $b_{i}, i=1, \ldots, n$, are set equal to the input cost shares in the reference time period. ${ }^{10}$ This functional form is attractive because it is a flexible functional form (Diewert and Wales [1988]) that retains flexibility under the imposition of concavity with respect to user costs.

Based on the specified cost function, (11), and dividing (10) by output quantity, $i$ th 
investment demand per unit of output, or the $i$ th investment intensity, becomes:

$$
\begin{aligned}
\frac{v_{i}}{y_{t}}=h_{i}^{-1} & \left\{\beta_{i}+\frac{\sum_{j=1}^{n} \beta_{i j} \omega_{j t}}{\sum_{i=1}^{n} b_{i} \omega_{i t}}-\frac{.5 b_{i} \sum_{i=1}^{n} \sum_{j=1}^{n} \beta_{i j} \omega_{i t} \omega_{j t}}{\left(\sum_{i=1}^{n} b_{i} \omega_{i t}\right)^{2}}\right. \\
& \left.+\beta_{i G} G_{t}+\beta_{t G} b_{i} G_{t}^{2}+\frac{\alpha_{i}}{y_{t}}+\frac{b_{i} \alpha_{t} t}{y_{t}}+\frac{b_{i} \alpha_{G} G_{t}}{y_{t}} b_{i} \alpha_{y y} y_{t}\right\}+\mu_{i} \frac{v_{i t-1}}{y_{t}} \quad i=1, \ldots, n .
\end{aligned}
$$

Notice that equation (12) does not contain an output efficiency parameter. Suppose this parameter, $\gamma$, is introduced, then the production function becomes $\gamma y_{t}=F\left(z_{t}, G_{t}, t\right)$, where $z_{t}$ is the vector of efficiency-adjusted inputs. However, this parameter is not identifiable. To see this, assume for simplicity technological change is neutral and constant, then $\gamma y_{t}=$ $F\left(z_{t}, G_{t}, t\right)=\beta F\left(z_{t}, G_{t}\right)$, and thus $y_{t}=\eta F\left(z_{t}, G_{t}\right)$, where $\eta=\beta / \gamma$, and so $\gamma$ is not identified. Thus without loss of generality $\gamma$ can be set to unity, and therefore the production function , $F$, actually embodies output efficiency. ${ }^{11}$

The next requirement for estimation, which involves the expectation generating processes for acquisition and hiring prices. It is assumed that price expectations follow a first order autoregressive process: ${ }^{12}$

$$
q_{i t+1}=\phi_{i}+\theta_{i} q_{i t}+e_{i t}, i=1, \ldots, n,
$$

where $\phi_{i}$, and $\theta_{i}$ are parameters, $e_{i t}$ is identically and independently distributed over time, and since expectations are rational, the expected value of $e_{i t}$ is zero. Equation set (13) implies in the current period $t$, that the $i$ th expected acquisition or hiring price in period $t+s$ is,

$$
q_{i t+s}^{e}=\frac{\phi_{i}\left(1-\theta_{i}^{s}\right)}{\left(1-\theta_{i}\right)}+\theta_{i}^{s} q_{i t}, i=1, \ldots, n .
$$

Equation set (14) shows the price expectations terms to be used in the user cost formulas. Substituting (14) into the right side of (6), expanding the geometric progression, and collecting terms, the user costs become:

$$
\omega_{i t}=h_{i}^{-1}\left[q_{i t} \frac{1-a d_{i} \theta_{i}}{1-a \mu_{i} \theta_{i}}+\frac{\phi_{i}}{1-\theta_{i}}\left(\frac{1-a d_{i}}{1-a \mu_{i}}-\frac{1-a d_{i} \theta_{i}}{1-a \mu_{i} \theta_{i}}\right)\right], i=1, \ldots, n,
$$

Specifying the price expectations processes reveals that the user costs are unobservable because of the technical efficiency parameters, $h_{i}=1 /\left(1-\mu_{i}\right)$, and the expectations parameters $\left(\phi_{i}, \theta_{i}\right)$. 
With the cost function and price expectations processes specified, the estimation model becomes (12) (with (15) defining the user costs), and (13). The errors, $u_{t}=\left(u_{1 t}, \ldots, u_{n t}\right)$, relating to equation set (12) are assumed to be identically, and independently distributed over time with zero expected value. ${ }^{13}$ In addition, with the errors from (13), which are $e_{t}=\left(e_{1 t}, \ldots, e_{n t}\right)$, let $E\left[\left(u_{t}, e_{t}\right)\left(u_{s}, e_{s}\right)^{T}\right]=\Theta$, for all $s, t$ if $s=t$, and 0 if $s \neq t$, where $\Theta$ is the positive definite covariance matrix. Equation sets (13) and (14) are jointly estimated by the Nonlinear Seemingly Unrelated Regression estimator, applied to data over the period from 1964 to 1997. There are three factors of production, labor, intermediate inputs or materials, and physical capital, and thus expressions (12) and (13) consist of six equations, three input intensity equations, and three equations relating to price expectations. The data for the Canadian food processors industry and the infrastructure capital are discussed and presented in the Appendix.

A number of versions of the model were estimated in order to conduct tests on the efficiency and expectations parameters. First, the model was estimated to determine whether technical efficiency between new and current inputs differ. Thus there were two versions; $h_{i} \neq 1$, or $\mu_{i} \neq 0$, and $h_{i}=1$, or $\mu_{i}=0 .{ }^{14}$ Second, each of the two versions were estimated with $A R(1)$ and constant (or static) price expectations processes. The bottom section of table 1 shows the results from a number of hypotheses tests. These results show that the hypothesis of no difference in technical efficiency, $h_{i}=1$, is rejected for each of the factors of production. ${ }^{15}$ Next, constant price expectations can also be rejected, since the price expectation parameter $\theta_{i}$ differ from one. ${ }^{16}$ To summarize, the results indicate that new factors are relatively more efficient than current inputs, and that efficiency levels differ among the new factors of production, while price expectations follow $A R(1)$ processes.

In addition a number of tests on the residuals are provided. Tests are conducted for nonspherical disturbances. First order, and combined first and second order serial correlation are rejected and $\mathrm{ARCH}$ is also rejected. ${ }^{17}$ The last test relates to the concavity of the cost function with respect to the user costs. Concavity imposed using the Wiley, Schmidt and Bramble [1973] technique, cannot be rejected.

The regression results for the preferred specification, that is with $A R(1)$, and $h_{i} \neq 1$,are 
presented in table 1. The estimates of the efficiency parameters suggest that technical efficiency levels increase with factors additions in the food processing industry. Moreover, since $h_{i}=1$ implies that efficiency does not change, then the rate of efficiency growth for the $i$ th input can be defined as $h_{i}-1$. By inverting the estimates of the $h_{i}^{-1}$ parameters in table 1 and subtracting 1, annual factor efficiency growth rates for the food processing industry are; 2.15 percent for labor, 4.70 percent for capital, and 0.20 percent for materials. Our findings indicate that the primary factors of production, namely labor and capital, exhibit efficiency improvements. These efficiency gains, which arise from labor and capital additions, dominate the efficiency-eroding adjustment costs associated with installing these new inputs into the production process. However, efficiency gains are modest for intermediate input additions, and so to the extent that efficiency improvements arise from new purchased inputs concomitantly these new input cause higher and offsetting costs of adjustment.

\section{ELASTICITIES OF FACTOR DEMAND AND COST}

Although the main concern of the paper is to investigate the effects of infrastructure on factor demands, cost, and productivity growth, since little is known about the production process of the Canadian food processing industry, we also provide price, output, and technology elasticities. First, the elasticity of demand for input $i, v_{i t}^{*}$ defined from equation (10), with respect to the user cost of input $j$, namely $\omega_{j t}$, is:

$$
\epsilon_{i j t}=\left[\partial v_{i t}^{*} / \partial \omega_{i t}\right]\left(\omega_{i t} / v_{i t}^{*}\right), \quad i=1, \ldots, n
$$

Moreover, since $z_{i t}=h_{i}\left(v_{i t}-\mu_{i} v_{i t-1}\right)$, then at the cost minimizing quantities the price elasticities of demand can be rewritten in terms of efficiency-adjusted input requirements as:

$$
\epsilon_{i j t}=h_{i}^{-1}\left[\partial z_{i t}^{*} / \partial \omega_{i t}\right]\left[\omega_{i t} /\left(h_{i}^{-1} z_{i t}^{*}+\mu_{i} v_{i t-1}\right)\right], \quad i=1, \ldots, n
$$

The price elasticities are reported in Table2. From this table we find that the own price elasticities (found in the diagonals of table 2) are all negative and highly inelastic. As typical of dynamic factor demand models the price elasticities of conditional factor demands, that 
is conditional on output quantity, are quite inelastic since these demand changes tend to operate through output quantity rather than through factor prices. Next, the cross price elasticities, which are the off-diagonal elements in table 2 , show the pattern of substitutes and complements. The two primary inputs, namely capital and labor are substitutes, while intermediate inputs are complementary to each of the primary factors in the Canadian food processing industry. These results are consistent with the observation over the last three decades of a secular decline in labor intensity accompanied by capital deepening, and an expanding role for intermediate inputs in food processing production.

The infrastructure capital, output and technology elasticities of factor demands are given by the following formulas:

$$
\eta_{i \kappa t}=h_{i}^{-1}\left[\partial z_{i t}^{*} / \partial \kappa_{t}\right]\left[\kappa_{t} /\left(h_{i}^{-1} z_{i t}^{*}+\mu_{i} v_{i t-1}\right)\right], \quad i=1,2, \ldots, n, \quad \kappa=G, y, t .
$$

In addition, from equation (8) the cost of efficiency-adjusted inputs in year $t$ is $c_{t}=$ $C\left(\omega_{1 t}, \omega_{2 t}, \ldots, \omega_{n t}, y_{t}, G_{t}, t\right)=\sum_{i=1}^{n} \omega_{i t} z_{i t}^{*}$. Since $z_{i t}^{*}=h_{i}\left(v_{i t}^{*}-\mu_{i} v_{i t-1}\right)$ then $c_{t}=\sum_{i=1}^{n} \omega_{i t} h_{i}\left(v_{i t}^{*}-\right.$ $\left.\mu_{i} v_{i t-1}\right)$.and so the elasticities of cost with respect to infrastructure capital, output and technology are:

$$
\eta_{c \kappa t}=\left[\partial c / \partial \kappa_{t}\right]\left(\kappa_{t} / c_{t}\right)=\sum_{i=1}^{n} s_{i t}\left[\partial z_{i t}^{*} / \partial \kappa_{t}\right] \kappa_{t} / z_{i t}^{*}=\sum_{i=1}^{n}\left(s_{i t} h_{i} v_{i t}^{*} / z_{i t}^{*}\right) \eta_{i \kappa t}
$$

where $s_{i t}=\omega_{i t} z_{i t}^{*} / c_{t}$, is $i$ th efficiency-adjusted cost share.

These elasticities are reported in Table 3. Growing infrastructure capital reduces labor requirements and increases the demand for capital. This result is consistent with the substitutability of primary factors of production as exhibited from the price elasticities. Moreover from table 3, public sector infrastructure capital is a substitute for the private sector intermediate inputs. Overall with respect to the cost of production, infrastructure capital is cost-reducing, as a 1 percent increase in infrastructure capital decreases cost by 0.16 percent. These results are consistent with other studies pertaining to manufacturing industries in many countries that relate infrastructure to production cost (see Seitz and Licht [1995] for Germany, Nadiri and Mamuneas [1994, 1996] for the US, Zugasti et al. [2001] for Spain and Rovolis and Spence [2002] for Greece). 
Next increases in output quantity illustrate the same factor demand pattern as for growing infrastructure capital, although the output effects are relatively more elastic, as output is the major determinant of conditional factor demands. In particular, a $1 \%$ increase in output reduces cost by $0.94 \%$. Since the degree of returns to scale is the inverse of the output elasticity of cost then Canadian food processors exhibit slightly increasing returns to scale of $1.06 .^{18}$ The last row of table 3 shows the effects of disembodied technological change. In the food processing industry there has been little evidence of technological change, as the technology effects are highly inelastic and indeed almost nonexistent.

Another way that the effects of public infrastructure can be understood is by determining the benefit-cost ratio associated with infrastructure investment. To calculate this benefitcost ratio consider the amount by which production costs change when infrastructure capital increases by $\Delta G_{t}$ :

$$
\Delta c_{t}=\left[\partial c / \partial G_{t}\right] \Delta G_{t}
$$

Now the nominal value of public infrastructure in year $t$ is $G_{t}^{n}=w_{g t} G_{t}$, where $w_{g t}$ is the deflator for the public infrastructure stock. Since $w_{g t}$ is fixed then $\Delta G_{t}=\Delta G_{t}^{n} / w_{g t}$, and so the benefit-cost $(B C)$ ratio associated with a $\$ 1=\Delta G_{t}^{n}$ increase in infrastructure capital is:

$$
B C=-\Delta c_{t}=-\left[\partial c / \partial G_{t}\right] / w_{g t}
$$

We find on average that the benefit-cost ratio is $\$ 0.032$. In other words, an investment of one dollar in public infrastructure elicits a benefit of over $\$ 0.03$ to Canadian food processors.

\section{PRODUCTIVITY GROWTH AND DECOMPOSITION}

In order to derive TFP growth, begin with the general cost function given by (9), $C\left(\omega_{1 t}, \ldots, \omega_{n t}, y_{t}, G_{t}, t\right)$. Since the specification of this function, given by expression (11), is second order, with time-invariant second order parameters, the cost difference between periods $s$ and $t$, defined as $c_{t}-c_{s}$, consists only of first order terms (see Bernstein Mamuneas 
and Pashardes [2004], and the survey by Good, Nadiri and Sickles [1997]). Thus,

$$
\begin{aligned}
c_{t}-c_{s} & =.5 \sum_{i=1}^{n}\left(\frac{\partial c_{t}}{\partial \omega_{i t}}+\frac{\partial c_{s}}{\partial \omega_{i s}}\right)\left(\omega_{i t}-\omega_{i s}\right)+.5\left(\frac{\partial c_{t}}{\partial y_{t}}+\frac{\partial c_{s}}{\partial y_{s}}\right)\left(y_{t}-y_{s}\right) \\
& +.5\left(\frac{\partial c_{t}}{\partial G_{t}}+\frac{\partial c_{s}}{\partial G_{s}}\right)\left(G_{t}-G_{s}\right)+.5\left(\frac{\partial c_{t}}{\partial t}+\frac{\partial c_{s}}{\partial s}\right)(t-s) .
\end{aligned}
$$

Next, from (9), with $\partial c_{t} / \partial \omega_{i t}=z_{i t}^{*}, i=1, \ldots, n$, define the mean value as $z_{i m}^{*}=.5\left(z_{i t}^{*}+z_{i s}^{*}\right)$, (subscript $m$ denotes the mean value of a variable) then collecting terms, (22) becomes

$$
\begin{aligned}
& .5\left[\sum_{i=1}^{n} \frac{\omega_{i t} z_{i t}^{*}\left(z_{i t}^{*}-z_{i s}^{*}\right) z_{i m}^{*}}{z_{i m}^{*} z_{i t}^{*}}+\sum_{i=1}^{n} \frac{\omega_{i s} z_{i s}^{*}\left(z_{i t}^{*}-z_{i s}^{*}\right) z_{i m}^{*}}{z_{i m}^{*} z_{i s}^{*}}\right] \\
& =.5\left(\frac{\partial c_{t}}{\partial y_{t}}+\frac{\partial c_{s}}{\partial y_{s}}\right)\left(y_{t}-y_{s}\right)+.5\left(\frac{\partial c_{t}}{\partial G_{t}}+\frac{\partial c_{s}}{\partial G_{s}}\right)\left(G_{t}-G_{s}\right)+.5\left(\frac{\partial c_{t}}{\partial t}+\frac{\partial c_{s}}{\partial s}\right)(t-s) .
\end{aligned}
$$

Next multiplying $(23)$ by -1 , adding $(c / y)_{m} y_{m}\left(y_{t}-y_{s}\right) / y_{m}=.5\left[c_{t} / y_{t}+c_{s} / y_{s}\right] y_{m}\left(y_{t}-\right.$ $\left.y_{s}\right) / y_{m}$ to both sides, and collecting terms yields

$$
\begin{aligned}
& \left(\frac{c}{y}\right)_{m} y_{m} \frac{\left(y_{t}-y_{s}\right)}{y_{m}}-.5\left[\sum_{i=1}^{n} \frac{s_{i t}\left(z_{i t}^{*}-z_{i s}^{*}\right) z_{i m}^{*} c_{t}}{z_{i m}^{*} z_{i t}^{*}}+\sum_{i=1}^{n} \frac{s_{i s}\left(z_{i t}^{*}-z_{i s}^{*}\right) z_{i m}^{*} c_{s}}{z_{i m}^{*} z_{i s}^{*}}\right] \\
& =.5\left[\left(1-\rho_{y t}^{-1}\right)\left(\frac{c}{y}\right)_{t}+\left(1-\rho_{y s}^{-1}\right)\left(\frac{c}{y}\right)_{s}\right]\left(y_{t}-y_{s}\right) \\
& +.5\left(\xi_{g t}\left(\frac{c}{G}\right)_{t}+\xi_{g s}\left(\frac{c}{G}\right)_{s}\right)\left(G_{t}-G_{s}\right) \\
& +.5\left(\xi_{\nu t} c_{t}+\xi_{\nu s} c_{s}\right)(t-s),
\end{aligned}
$$

where $s_{i t}=\omega_{i t} z_{i t}^{*} / c_{t}$ is the cost share for the $i$ th efficiency-adjusted factor, $\rho_{y t}=\left[\left(\partial c_{t} / \partial y_{t}\right)\right.$ $\left./\left(y_{t} / c_{t}\right)\right]^{-1}$ is the degree of returns to scale, $\xi_{g t}=-\left(\partial c_{t} / \partial G_{t}\right)\left(G_{t} / c_{t}\right)$ is the rate of cost reduction with respect to infrastructure capital and $\xi_{\nu t}=-\left(\partial c_{t} / \partial t\right) / c_{t}$ is the input-based rate of technological change.

The efficiency-adjusted TFP growth between periods, $s$ and $t$ is defined as, $\operatorname{FF}^{e}(s, t)=$ $\dot{Y} / Y-\dot{Z} / Z$ where

$$
\dot{Z} / Z=.5\left[\sum_{i=1}^{n} \frac{s_{i t}\left(z_{i t}^{*}-z_{i s}^{*}\right)}{z_{i m}^{*}} \frac{\left(z_{i m}^{*} / y_{m}\right)(c / y)_{t}}{\left(z_{i t}^{*} / y_{t}\right)(c / y)_{m}}+\sum_{i=1}^{n} \frac{s_{i s}\left(z_{i t}^{*}-z_{i s}^{*}\right)}{z_{i m}^{*}} \frac{\left(z_{i m}^{*} / y_{m}\right)(c / y)_{s}}{\left(z_{i s}^{*} / y_{s}\right)(c / y)_{m}}\right]
$$

is the growth rate of efficiency-adjusted factors, and output growth is $\dot{Y} / Y=\left(y_{t}-y_{s}\right) / y_{m}$. With this definition, divide $(24)$ by $(c / y)_{m} y_{m}$, to obtain the following equation for efficiency- 
adjusted TFP growth:

$$
\begin{aligned}
\operatorname{TFPG}^{e}(s, t) & =.5\left[\left(1-\rho_{y t}^{-1}\right)\left(\frac{c}{y}\right)_{t}+\left(1-\rho_{y s}^{-1}\right)\left(\frac{c}{y}\right)_{s}\right] \frac{\dot{Y} / Y}{(c / y)_{m}} \\
& +.5\left[\xi_{g t}\left(\frac{c}{y}\right)_{t}\left(\frac{y}{G}\right)_{t}+\xi_{g s}\left(\frac{c}{y}\right)_{s}\left(\frac{y}{G}\right)_{s}\right] \frac{(G / y)_{m} \dot{G} / G}{(c / y)_{m}} \\
& +.5\left[\xi_{\nu t}\left(\frac{c}{y}\right)_{t} y_{t}+\xi_{\nu s}\left(\frac{c}{y}\right)_{s} y_{s}\right] \frac{(t-s)}{(c / y)_{m} y_{m}}
\end{aligned}
$$

where the growth of infrastructure capital is $\dot{G} / G=\left(G_{t}-G_{s}\right) / G_{m}$. Expression (25) indicates that efficiency-adjusted TFP gains originate from three sources; increasing returns to scale associated with positive output growth, cost reduction due to infrastructure capital, and positive rates of technological change. ${ }^{19}$

Expression (25) captures the contribution of infrastructure capital to efficiency-based TFP growth. However much of the analysis of infrastructure capital and productivity considers TFP growth defined in terms of observed inputs, that is $\operatorname{TFP} G^{o}(s, t)=\dot{Y} / Y-\dot{V} / V$, where $\dot{V} / V$ is the measured or observed input growth rate such that

$$
\dot{V} / V=.5\left[\sum_{i=1}^{n} \frac{\varphi_{i t}\left(v_{i t}-v_{i s}\right)}{v_{i m}} \frac{\left(v_{i m} / y_{m}\right)(\varsigma / y)_{t}}{\left(v_{i t} / y_{t}\right)(\varsigma / y)_{m}}+\sum_{i=1}^{n} \frac{\varphi_{i s}\left(v_{i t}-v_{i s}\right)}{v_{i m}} \frac{\left(v_{i m} / y_{m}\right)(\varsigma / y)_{s}}{\left(v_{i s} / y_{s}\right)(\varsigma / y)_{m}}\right] .
$$

where $\varphi_{i t}=w_{i t} v_{i t} / \varsigma_{t}$ is the observed $i$ th factor cost share, $\varsigma_{i t}=\sum_{i=1}^{n} w_{i t} v_{i t}$ is the observed factor cost, $w_{i t}$ is the $i$ th observed factor price (defined by $w_{i t}=q_{t}-a q_{i t+1}^{e}\left(1-\delta_{i}\right)$ ).

Using the definitions of efficiency-adjusted and measured TFP growth, along with expression (25), the following establishes the link between the two rates:

$$
\begin{aligned}
\operatorname{TFPG}^{o}(s, t) & =.5\left[\left(1-\rho_{y t}^{-1}\right)\left(\frac{c}{y}\right)_{t}+\left(1-\rho_{y s}^{-1}\right)\left(\frac{c}{y}\right)_{s}\right] \frac{\dot{Y} / Y}{(c / y)_{m}} \\
& +.5\left[\xi_{g t}\left(\frac{c}{y}\right)_{t}\left(\frac{y}{G}\right)_{t}+\xi_{g s}\left(\frac{c}{y}\right)_{s}\left(\frac{y}{G}\right)_{s}\right] \frac{(G / y)_{m} \dot{G} / G}{(c / y)_{m}} \\
& +.5\left[\xi_{\nu t}\left(\frac{c}{y}\right)_{t} y_{t}+\xi_{\nu s}\left(\frac{c}{y}\right)_{s} y_{s}\right] \frac{(t-s)}{(c / y)_{m} y_{m}} \\
& +\left[\left(\frac{\dot{Z}}{Z}\right)-\left(\frac{\dot{V}}{V}\right)\right] .
\end{aligned}
$$

Equation (26) shows that the wedge between measured and efficiency-adjusted TFP growth 
equals the difference between efficiency-adjusted and observed input growth, $\left(\frac{\dot{Z}}{Z}\right)-\left(\frac{\dot{V}}{V}\right)$. This difference is termed the factor efficiency effect.

Measured productivity growth rates and it's decomposition based on expression (26 are presented in Table 4 for the period 1965-1996, and for each five-year sub-periods. Over the period 1965-1996 the average annual rate of observed TFP growth was 0.26 percent. This is a relatively low rate of growth. Further, this meager rate persisted through the period from 1965 to 1975, but then doubled over the following decade. Although the productivity performance was unspectacular, only in the second half of the 1980's, which was a period of relatively slow output growth, did measured TFP growth turn negative. However, through the 1990's measured productivity growth returned to its historical, but low, rate.

The difference between the measured and efficiency-based TFP growth rates can be discerned by subtracting the factor efficiency effect in table 4 from observed TFP growth. This difference equals efficiency-based growth. Equivalently as noted in expression (25), summing the scale, technology and infrastructure columns in table 4 provides for efficiencybased TFP growth. The average annual rate of efficiency-based growth was 0.29 percent, which slightly exceeded the observed rate. This means that, on average, improvements in factor efficiency do not play a major role in contributing to productivity performance. However, table 4 shows infrastructure capital, to be an important contributor to TFP growth. Its average annual contribution is 0.5 percentage points, which is nearly double the rate of measured TFP growth. Further, our findings indicate that infrastructure capital accumulation offsets the decelerating effects of disembodied technology, and therefore in terms of TFP performance, infrastructure investment acts a substitute for technological change in food processing.

\section{CONCLUSION}

The results from this paper show that public infrastructure capital generates important effects on the production techniques, cost of production and productivity growth for Canadian food processors. Changes in public infrastructure led to changes in the mix of inputs 
used by food processors, inducing reductions in the demand for labor and intermediate inputs, and increases in the demand for capital A 1 percent increase in infrastructure capital decreased labor requirements by 0.07 percent. This input effect was relatively more inelastic compared to the other two factors of production. In absolute value terms the increase in capital and decrease in materials were respectively 2.5 and 3 times greater than the labor elasticity. Thus food processors employed relatively fewer workers, purchased relatively less intermediate inputs, and used relatively more capital than they would have otherwise in the absence of infrastructure investment.

Infrastructure investment was cost-reducing. A 1 percent increase in public infrastructure decreased production cost by 0.16 percent. Indeed from the benefit-cost ratio a $\$ 1$ increase in infrastructure capital reduced cost by $\$ 0.03$. Applying the results on factor demands, public infrastructure provision tended to lower costs of production by changing the way in which output is produced, and particularly by inducing reductions in employment and intermediate inputs.

Measured TFP growth for Canadian food processors was 0.26 percent per year on average between 1964 and 1996. Although growth was low, nevertheless it was generally positive over the period. Consistent with its cost-reducing effects, public infrastructure growth enhanced productivity performance. Infrastructure capital, was a major contributor to TFP growth. Its average annual contribution was 0.5 percentage points, which double the rate of measured TFP growth. Moreover, infrastructure capital accumulation offset the decelerating effects of disembodied technology, so that infrastructure investment acted as a substitute for technological change in the generation of productivity gains. 


\section{APPENDIX: DATA DESCRIPTION}

The data is for the period $1963-1997$. The main factor limiting the time series is the information from Statistics Canada's KLEMS database, which extends to 1997 on a consistent basis. Gross output data are defined in current dollars as the value of shipments (sales) plus the value of any change in inventories. The concept of gross output comes from the following expression in nominal value terms:

$$
B E G_{t}+P R O D_{t}-E N D_{t} \equiv S H I P_{t}+I N T D_{t}
$$

where: $B E G_{t}$ is the inventory that producers hold at the beginning of year $t, P R O D_{t}$ is the output produced in year $t, E N D_{t}$ is the inventory held by producers at the end of year $t, S H I P_{t}$ is the manufacturing shipments (sales) in year $t$ and $I N T D_{t}$ is the intermediate inputs (drawn from beginning inventories or production) used in the production of output in year $t .^{20}$ Thus, the left-hand side of the nominal value of the supply-demand balance identity represents gross supply and the right-hand side represents gross demand. Gross output comes from a rearrangement of the previous expression:

$$
P R O D_{t} \equiv S H I P_{t}+I N T D_{t}+\left(E N D_{t}-B E G_{t}\right)
$$

meaning that gross output is equal to production, which in turn is defined as the sum of shipments, intermediate demand and change in inventory $\left(E N D_{t}-B E G_{t}\right)$ in that year. ${ }^{21}$ Constant dollar gross output data, $y_{t}$, is calculated by dividing current dollar value of gross output by the output price deflator.

Capital input quantities $v_{K t}$ are derived by dividing the current dollar value of the stock for each of the 17 asset groups by the capital stock deflator for that group, and then forming a Fisher index to derive the capital input. The Fisher aggregate capital input is calculated by first multiplying acquisition prices by their respective observed input quantities, and taking the sum of these values. This sum is then divided by the Fisher aggregate acquisition price. Input quantities of non-capital inputs $\left(v_{L t}\right.$ and $\left.v_{M t}\right)$ are derived by dividing the current 
Table A1: Food Processing Industry Data

Descriptive Statistics (1963-1997)

\begin{tabular}{lcccc}
\hline \hline Variable & Mean & Std. Dev. & Min. & Max. \\
\hline Output $\left(y_{t}\right)$ & 34990.51 & 6546.37 & 22362.91 & 45256.27 \\
Labor, $\left(v_{L t}\right)$ & 7144.20 & 291.94 & 6570.52 & 7715.51 \\
Capital, $\left(v_{K t}\right)$ & 7692.97 & 3074.11 & 3272.27 & 12161.60 \\
Materials, $\left(v_{M t}\right)$ & 24170.00 & 4678.53 & 15392.39 & 32033.67 \\
Infrastructure .Capital $\left(G_{t}\right)$ & 159100.59 & 67552.91 & 55597.45 & 258082.91 \\
Labor price $\left(q_{L t}\right)$ & 0.5376 & 0.3442 & 0.1104 & 1.0513 \\
Capital price $\left(q_{K t}\right)$ & 0.7329 & 0.2453 & 0.3928 & 1.1541 \\
Material price $\left(q_{M t}\right)$ & 0.7039 & 0.3298 & 0.2568 & 1.1983 \\
\hline \hline
\end{tabular}

dollar expenditure data for labour, and intermediate inputs (which is a Fisher aggregate of energy, materials and services) by the hiring or acquisition prices for these variables. Acquisition prices for each of the 17 capital asset types are defined as investment deflators and are obtained from the Investment and Capital Stock Division at Statistics Canada. Hiring prices for labour and acquisition prices for energy, materials and purchased services are taken from the Statistics Canada KLEMS database. Lastly, infrastructure capital stock, $G_{t}$, data are defined as an aggregation of stocks held by the Public Administration sector (NAICS code 910000), and covers a total of 21 asset groups. ${ }^{22}$

The Food processing indusry is one of the most important manufacturing subsectors in Canada. As Figure 1 shows the value of total shipments by food processors has been exceeded only by makers of transportation equipment. Food processors' share of total shipments averaged 13 percent. Figure 2 shows that the number of employees working for food processors has exceeded that in any other subsector in manufacturing, with an average share of 12 per cent of all employment in manufacturing. From Figure 3 acquisition prices for capital and intermediate inputs (which is the energy, materials and services aggregate) 


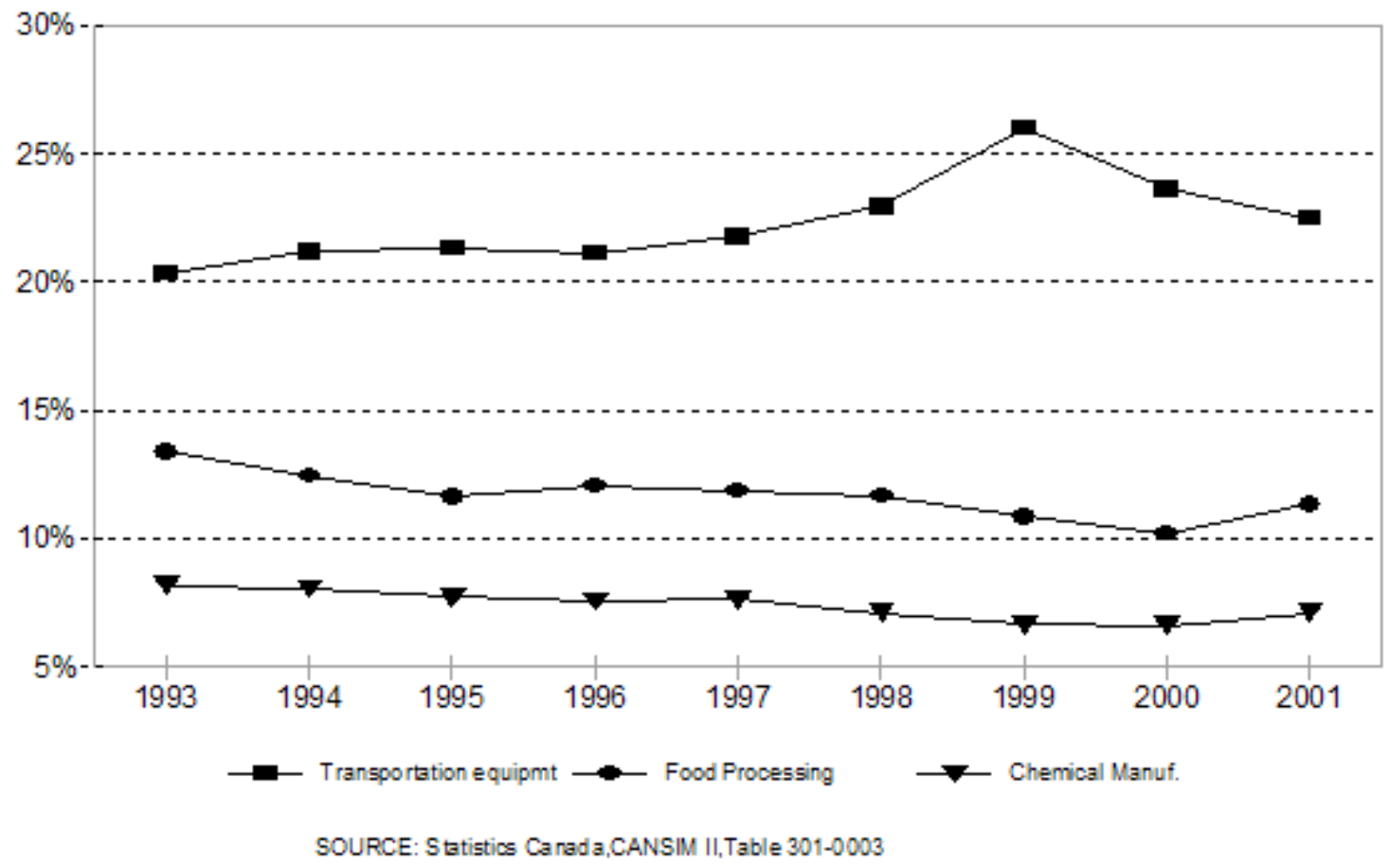

Fig. 1: Share of Shipments in Canadian Manufacturing Sector, Top Three Producers 1963-2002 


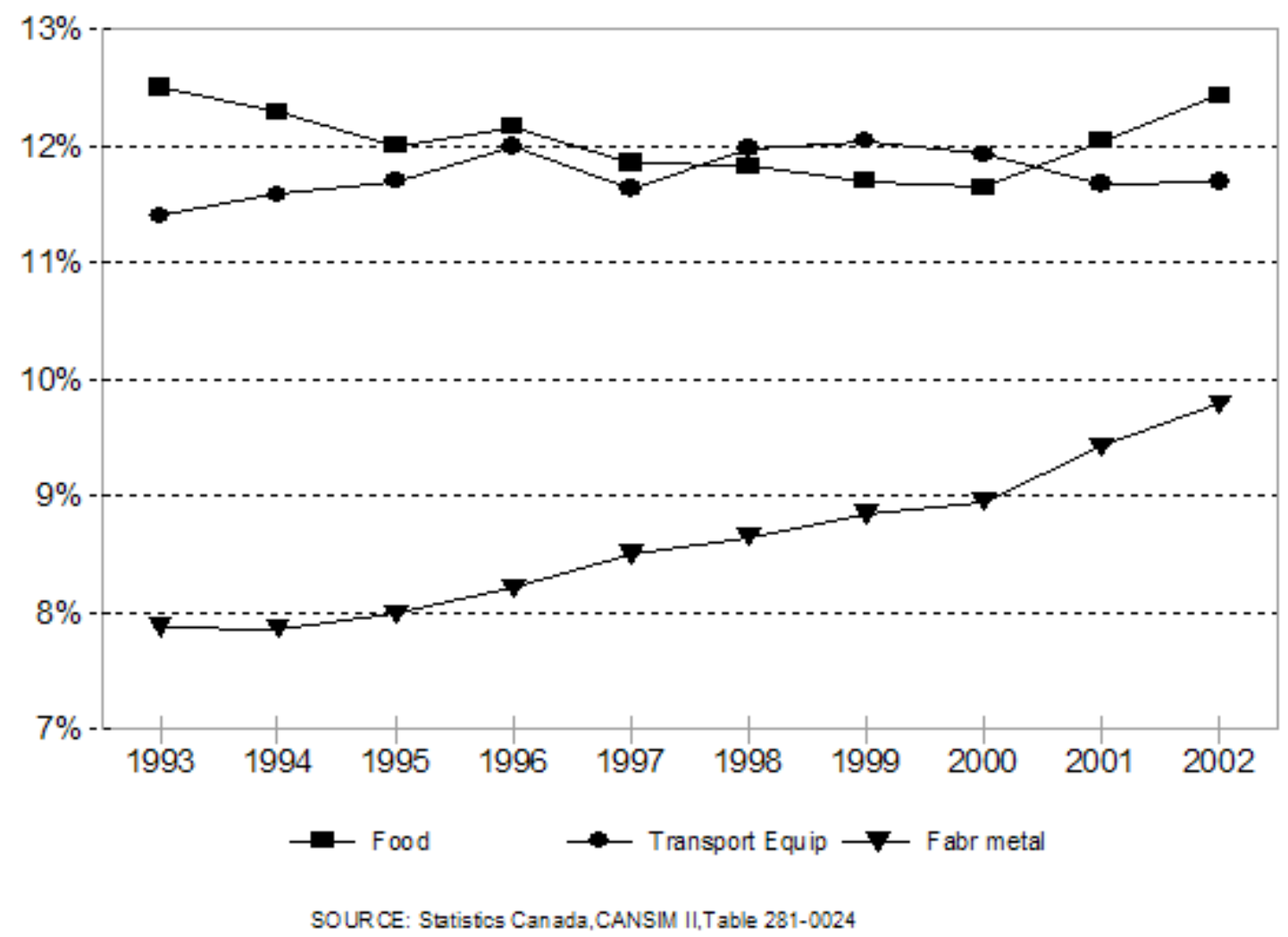

Fig. 2: Share of Employment in Canadian Manufacturing Sector, Top Three EMPLOYERS, 1963-2002 


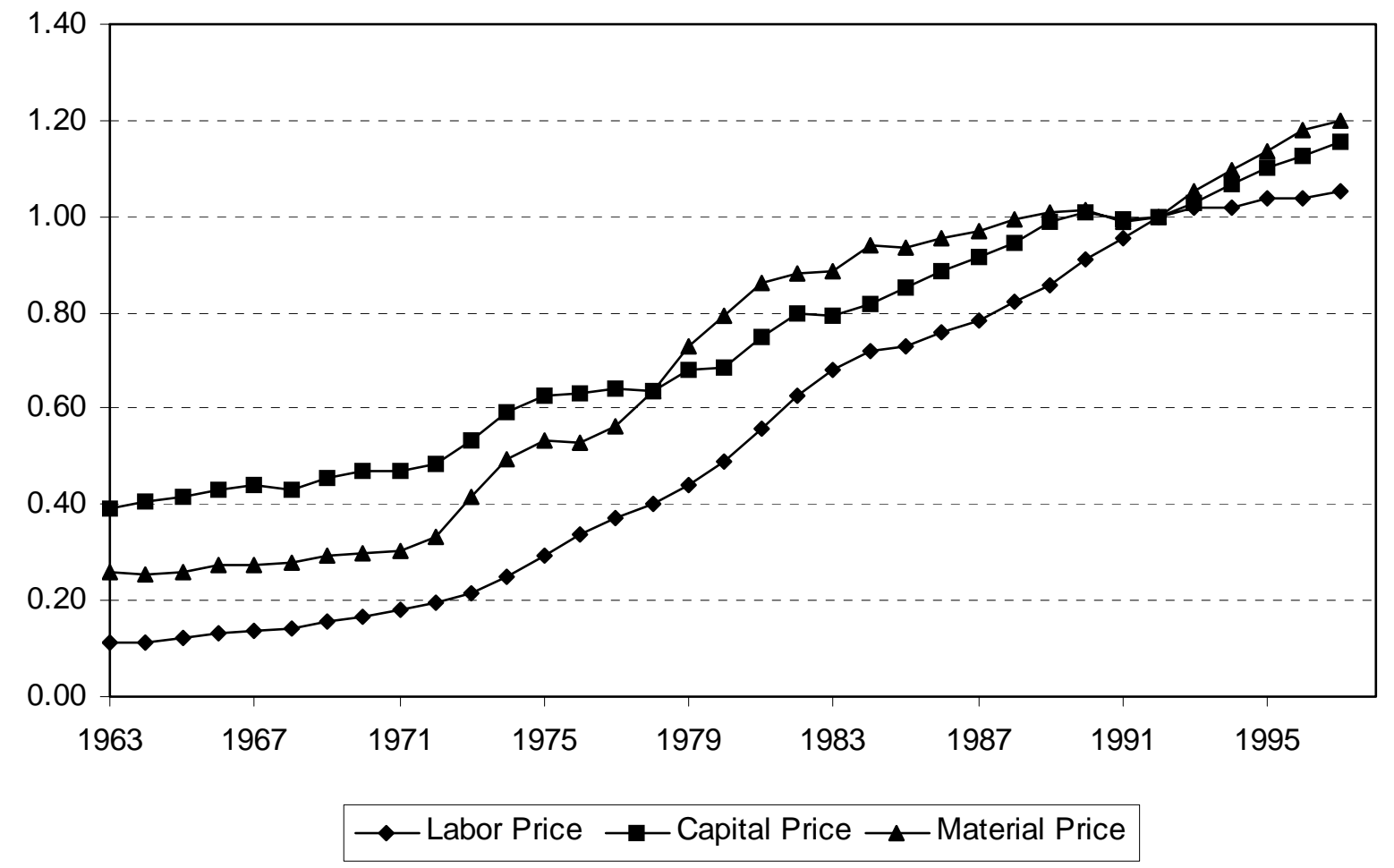

Fig. 3: Acquisition/Hiring Prices, Food Processing Industry, 1963-1997 


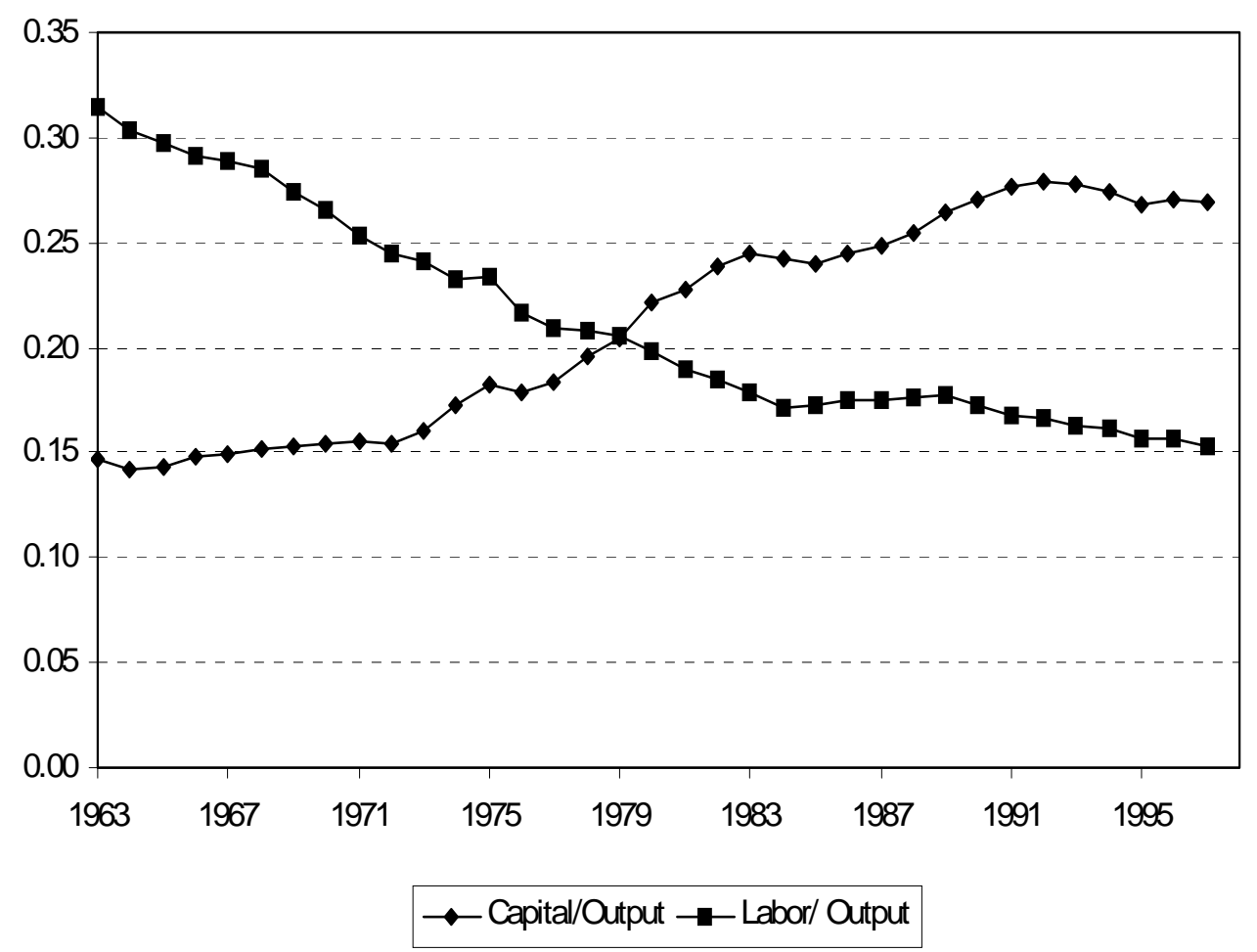

Fig. 4: Capital/Output v.s. Labor/Output Ratios, Food Processing Industry, 1963-1997 
and the hiring price for labour increased more or less consistently from year to year over the whole sample, with acquisition prices fluctuating more than the hiring price for labour. The latter price, however, shows a much slower rate of annual increase in the last five years of the sample. Another feature of the data is the trend in observed input-output ratios for capital and labor - see Figure 4. Here, the difference in the annual changes of these variables is striking, with the former ratio increasing more-or-less consistently over the whole sample and the latter decreasing consistently. Since the material/output ratio is relatively constant between 1963 and 1997, the increase in capital intensity has come about at the expense of labour. This pattern is further supported and consistent with the relative movement of acquisition and hiring prices. 


\section{ENDNOTES}

${ }^{1}$ Within the North American Industry Classification System (NAICS) the food processing industry is 311000. Within the 1980 Standard Industrial Classification (1980 SIC) it is group 10 of Division E.

${ }^{2}$ The production function has the usual properties as described for example in chapter 5 of Mas Collel, Whinston and Green [1995].

${ }^{3}$ It is not possible for $h_{i} i=1, \ldots, n$ to be negative. This would imply negative marginal products in equilibrium, as determined from the first order conditions denoted by equation (6) below. Also the framework admits negative input changes. Here marginal products decline. This reduction is due to adjustment costs and relative factor efficiency deterioration.

${ }^{4}$ Notice that parameterizing the technical efficiency of new inputs relates to their disembodied characteristics in the production process. It is not a parametrization of embodied quality improvements. The basis for the current model emanates from the literature on factor augmenting technical change. However, in that framework efficiency growth, is equally applicable to "old" and "new" inputs.

${ }^{5}$ Using equation (2), the production function can be written in the following manner:

$$
y_{t}=F\left(z_{1 t}, z_{2 t}, \ldots, z_{n t}, G_{t}, t\right)
$$

where $z_{i t}$ is the efficiency-adjusted quantity of input $i$, defined by:

$$
\left.z_{i t}=h_{i} x_{i t}+\left(1-h_{i} \delta_{i}\right) v_{i t-1}\right)
$$

and so:

$$
z_{i t}=v_{i t-1}+h_{i}\left(x_{i t}-\delta_{i} v_{i t-1}\right)
$$

Notice that the difference between $v_{i t}$ and $z_{i t}$ is in the treatment of net investment, which is weighted here by $h_{i}$. 
${ }^{6}$ Efficiency-adjusted inputs could also be defined in this model by making an adjustment to gross additions instead of net additions, i.e. by defining $z_{i t}$ as:

$$
z_{i t}=h_{i} x_{i t}+\left(1-\delta_{i}\right) v_{i t-1}
$$

For capital, data are available for $x_{i t}$, which is investment. But for other inputs, equivalent investment data are rarely available. Labour data, for example, are usually reported as total employment or hours, i.e. only $v_{i t}$ and $v_{i t-1}$ are observed. Thus, net additions rather than gross additions are used for practical reasons. It is likely, moreover, that even if data were available for the gross adjustment model that it would yield similar results to the net adjustment model. Pindyck and Rotemberg [1983], have shown that the two models, when applied in an adjustment cost context have led to results for capital that are quite similar.

${ }^{7} \mathrm{As}$ is common, we are assuming that the discount rate is constant (see Nadiri and Prucha [2001], for a survey).

${ }^{8}$ At this point there is no need to specify the expectations generating processes associated with acquisition or hiring prices. The processes need only depend on exogenous variables.

${ }^{9}$ Equation (6) also shows that in equilibrium the efficiency parameters cannot be nonpositive, that is $h_{i} \not \leq 0$, and so $\mu_{i} \nsupseteq 1$. Otherwise nonpositive marginal products result.

When $1>\mu_{i}>0\left(h_{i}>1\right)$, to ensure the condition $a \mu_{i}<1$ is met, the following must hold (for all positive discount rates $\rho$ ):

$$
h_{i}>-1 / \rho,
$$

which is met by default since in this case $h_{i}>1$.

When $\mu_{i}<0\left(0<h_{i}<1\right)$, to ensure the condition $a \mu_{i}>-1$ is met, the following must hold:

$$
h_{i}>1 /(2+\rho) \text {, }
$$

which represents the only constraint on $h_{i}$ for the condition $\left|a \mu_{i}\right|<1$ to be satisfied.

${ }^{10}$ The reference time period is 1992 . This is the year that price indexes are normalized to unity. 
${ }^{11}$ Output measurement error could also be an issue. This has been investigated in a number of papers. Lichtenberg and Griliches [1989], and Siegel [1995] conclude that the degree of output mismeasurement is relatively constant over time. This result implies that output mismeasurement error does not contribute to the mismeasurement of productivity changes over time.

${ }^{12}$ The model was also estimated under the assumption that prices followed second order autoregressive processes. However first order processes could not be rejected as the expectations generating mechanisms.

${ }^{13}$ Additive errors in the factor demand equations reasonably arise from three sources (see for example the survey by Nadiri and Prucha [1998] and Berndt [1991]); measurement errors (such as in acquisition and hiring prices), optimizing errors (producers operate suboptimally), or technology shocks (arising from randomness in the technology).

${ }^{14}$ The inverse of the efficiency parameters were estimated, since they appear as inverses in the first order conditions, (6).

${ }^{15}$ The models with $A R(1)$ expectations are nested, as are the models with constant price expectations. This feature justifies the use of Likelihood Ratio $(L R)$ tests to determine the preferred specification. The $L R$ statistic has been small sample corrected. The calculation of the $L R$ test statistic is from Sims [1980]. $L R=2 *(L L U-L L R) *[(T-k) / T]$, where $L L U$ is the $\log$ of the likelihood function from the unrestricted model, $L L R$ is the $\log$ of the likelihood from the restricted model, $T$ is the number of observations, and $k$ is the number of parameters in the unrestricted model divided by the number of equations.

${ }^{16}$ Price expectation equations, (13), were estimated in first differences, because in level form the constants, denoted by the $\phi_{i}$ parameters, were insignificant.

${ }^{17}$ For the development of these tests see Breusch and Pagan [1980], and Engle [1984]. The absence of serial correlation for the preferred specification is a further argument in favor of this formulation.

${ }^{18}$ Since the production function, defined by $(1)$, is $y_{t}=F\left(z_{1 t}, \ldots, z_{n t}, G_{t}, t\right)$, then returns 
to scale is defined in terms of efficiency-adjusted inputs.

${ }^{19}$ Efficiency adjusted TFP growth is based on the assumption, following the results of Lichtenberg and Griliches [1989], Siegel [1995], Bernstein, Mamuneas, Pashardes [2004] that output measurement error does not significantly affect productivity growth.

${ }^{20}$ For example, flour produced by a miller might be sold to an enterprise in an industry other than food processing (e.g. to a wholesaler) or it could be sold to an enterprise that is also in the food processing industry (such as a bakery). In the former case, the flour would enter the identity as an intermediate input (i.e. in $I N T D_{t}$ ) while in the latter case, it would enter as a shipment (i.e. in $S H I P_{t}$ ). The difference is important, since intermediate inputs are included in the materials input component of the KLEMS data (along with materials purchased from outside the food processing industry) - these inputs are thus included both as part of the materials input and as part of gross output, while shipments only appear as part of gross output.

${ }^{21}$ Since the food processing industry is comprised of several sub-industries (in the KLEMS database there are seven of these), aggregation of output is valid if output in the subindustries grew at approximately the same rate. While growth rates did vary between sub-industries, the rates of output growth for meat processing and for dairy processing which together represented nearly $50 \%$ of industry output over the sample - were quite similar. The features of these sub-industry series provides support for the use of a single aggregate output.

${ }^{22}$ This sector is comprised of three subsectors: Federal Government Public Administration (NAICS code 911000); Provincial and Territorial Public Administration (NAICS code 912000); and Local, Municipal and Regional Public Administration (NAICS code 913000). 


\section{REFERENCES}

Berndt, E.R. (1991). The Theory and Practice of Econometrics, Reading: Addison-Wesley.

Bernstein, J. I., T. P. Mamuneas and P. Pashardes. (2004). "Technical Efficiency and U.S. Manufacturing Productivity Growth", The Review of Economics and Statistics. 86: 402-412.

Breusch, T. S., and A. R. Pagan (1980) "The Lagrange Multiplier Test and its Application to Model Specification in Econometrics", Review of Economic Studies, 47, 239-254.

Diewert, W. E. (1982). "Duality Approaches to Microeconomic Theory", in Arrow, K.J. and M.D. Intriligator (eds.), Handbook of Mathematical Economics, Volume II, Amsterdam: North-Holland.

Diewert, W. E. and T. J. Wales (1988) "A Normalized Quadratic Semiflexible Functional Form," Journal of Econometrics, 37, 327-342..

Engle, R. F. (1984) "Wald, Likelihood Ratio, and Lagrange Multiplier Tests in Econometrics", in Z. Griliches and M. Intriligator, eds., Handbook of Econometrics, Vol. 2, Elsevier Science Publishers, Amsterdam, The Netherlands.

Good, D. H., M. I. Nadiri, and R. Sickles (1997) "Index Number and Factor Demand Approaches to the Estimation of Productivity", in H. Pesaran and P. Schmidt, eds. Handbook of Applied Econometrics Vol. II-Microeconometrics, Malden, MA: Blackwell Publishers, 14-80.

Lichtenberg, Frank R., and Z. Griliches (1989) "Errors of Measurement in Output Deflators", Journal of Business and Economic Statistics, 7, 1-9.

Mas-Collel, A., M. Whinston, and J. Green (1995) Microeconomic Theory, New York: Oxford University Press. 
Nadiri, M.I and T.P. Mamuneas (1996). "Contribution of Highway Capital to Industry and National Productivity Growth", report prepared for the U.S. Federal Highway Administration, September. (obtained from the Federal Highway Administration website via the URL http://www.fhwa.dot.gov/reports/growth.pdf).

Nadiri, M.I and T.P. Mamuneas (1994). "The Effects of Public Infrastructure and R\&D Capital on the Cost Structure and Performance of U.S. Manufacturing Industries", Review of Economics and Statistics, 76, 22-37.

Nadiri, M.I., and I.R. Prucha. (2001). "Dynamic Factor Demand Models and Productivity Analysis", in: E. Dean, M. Harper and C. Hulten (Eds.), New Directions in Productivity Analysis. University of Chicago Press, Chicago, 103-164.

Pindyck, R. S., and Julio J. Rotemberg (1983) "Dynamic Factor Demands and the Effects of Energy Price Shocks," American Economic Review, 73, 1066-1079.

Rovolis, A. and N. Spence (2002). "Duality Theory and Cost Function Analysis in a Regional Context: The Impact of Public Infrastructure Capital in the Greek Regions", The Annals of Regional Science, 36, 55-78..

Seitz, H. and G. Licht (1995). "The Impact of Public Infrastructure Capital on Regional Manufacturing Production Cost", Regional Studies, 29, 231-240

Siegel, D. (1995) "Errors of Measurement and the Recent Acceleration in Manufacturing Productivity Growth", The Journal of Productivity Analysis, 6, 297-320.

Sims, A. (1980) "Macroeconomics and Reality," Econometrica, 3, 1-48.

Wiley, D. E., W. H. Schmidt, and W. J. Bramble (1973) "Studies of a Class of Covariance Structure Models", Journal of American Statistical Association, 68, 317-323.

Zugasti, C.A.A., R.G. Garcia and J.S. Maldonato (2001). "The Efects of Public Infrastructure on the Cost Structure of Spanish Industries", Spanish Economic Review, 3, 131150. 
Table 1: Parameter Estimates And Hypothesis Testing

\begin{tabular}{|c|c|c|c|c|c|}
\hline Parameter & Estimate & Std. Error & Parameter & Estimate & Std. Error \\
\hline$\beta_{L}$ & $-2.6742 \mathrm{E}-01$ & $1.5012 \mathrm{E}-01$ & $\alpha_{L}$ & $1.2566 \mathrm{E}+04$ & $1.9646 \mathrm{E}+03$ \\
\hline$\beta_{K}$ & $-3.1067 \mathrm{E}-03$ & 1.9959E-02 & $\alpha_{K}$ & $1.5105 \mathrm{E}+02$ & $2.6382 \mathrm{E}+02$ \\
\hline$\beta_{M}$ & $-1.6842 \mathrm{E}-01$ & $6.2975 \mathrm{E}-01$ & $\alpha_{M}$ & $1.3705 \mathrm{E}+04$ & $5.2899 \mathrm{E}+03$ \\
\hline$\beta_{L L}$ & $-7.5115 \mathrm{E}-04$ & $2.9710 \mathrm{E}-03$ & $\alpha_{T}$ & $1.3698 \mathrm{E}+02$ & $8.5222 \mathrm{E}+01$ \\
\hline$\beta_{L K}$ & $-3.4327 \mathrm{E}-03$ & $6.9624 \mathrm{E}-03$ & $\alpha_{G}$ & $-7.2164 \mathrm{E}+03$ & $3.2084 \mathrm{E}+04$ \\
\hline$\beta_{L M}$ & $1.9973 \mathrm{E}-03$ & $5.0756 \mathrm{E}-03$ & $\alpha_{Y Y}$ & $3.1015 \mathrm{E}-05$ & $4.2134 \mathrm{E}-05$ \\
\hline$\beta_{K K}$ & $-1.5687 \mathrm{E}-02$ & $1.1354 \mathrm{E}-02$ & $h_{L}^{-1}$ & $3.1802 \mathrm{E}-01$ & $8.8084 \mathrm{E}-02$ \\
\hline$\beta_{K M}$ & $9.1273 \mathrm{E}-03$ & $6.6391 \mathrm{E}-03$ & $h_{K}^{-1}$ & $1.7544 \mathrm{E}-01$ & $6.9856 \mathrm{E}-02$ \\
\hline$\beta_{M M}$ & $-5.3107 \mathrm{E}-03$ & $6.1259 \mathrm{E}-03$ & $h_{M}^{-1}$ & $8.3662 \mathrm{E}-01$ & $6.3132 \mathrm{E}-02$ \\
\hline$\beta_{L G}$ & 7.0301E-02 & $2.0892 \mathrm{E}-01$ & $\theta_{L}$ & $9.1798 \mathrm{E}-01$ & $6.4775 \mathrm{E}-02$ \\
\hline$\beta_{K G}$ & $1.5247 \mathrm{E}-02$ & $2.4814 \mathrm{E}-02$ & $\theta_{K}$ & $6.5199 \mathrm{E}-01$ & $1.1596 \mathrm{E}-01$ \\
\hline$\beta_{M G}$ & 2.4373E-01 & $1.0284 \mathrm{E}+00$ & $\theta_{M}$ & $6.0601 \mathrm{E}-01$ & $9.8818 \mathrm{E}-02$ \\
\hline$\beta_{G G}$ & $-4.1733 \mathrm{E}-01$ & $5.7580 \mathrm{E}-01$ & & & \\
\hline Log of L.F. & 776.800 & & System $\boldsymbol{R}^{2}$ & 0.998 & \\
\hline \multicolumn{4}{|c|}{ Hypothesis Tests } & $\begin{array}{l}\text { Test Statistics } \\
(d . f .)\end{array}$ & $\begin{array}{l}\text { Critical values } \\
\chi_{.05}^{2}\end{array}$ \\
\hline \multicolumn{4}{|c|}{ No efficiency change $\left(h_{i}=1\right)$} & $W(3)=190.50$ & 7.82 \\
\hline \multicolumn{4}{|c|}{ Constant expectations } & $W(3)=17.92$ & 7.82 \\
\hline \multicolumn{4}{|c|}{ No efficiency change $\left(h_{i}=1\right) \&$ constant expectations } & $W(6)=212.44$ & 12.59 \\
\hline \multicolumn{4}{|c|}{ First and second order serial correlation } & $L M(72)=47.02$ & 92.81 \\
\hline \multicolumn{4}{|c|}{ First order serial correlation } & $L M(36)=40.73$ & 50.99 \\
\hline \multicolumn{4}{|c|}{ Second order serial correlation } & $L M(36)=34.47$ & 50.99 \\
\hline \multicolumn{4}{|c|}{ Heteroskedasticity $(A R C H)$} & $L M(12)=8.28$ & 50.99 \\
\hline \multicolumn{4}{|l|}{ Concavity } & $L R(3)=0.35$ & 7.82 \\
\hline
\end{tabular}


Table 2: Price Elasticities

Mean values, std. errors in parenthesis

\begin{tabular}{cccc}
\hline \hline & price & & \\
quantity & labor & capital & materials \\
\hline labor & -0.0027 & -0.0076 & 0.0103 \\
& $(0.0011)$ & $(0.0008)$ & $(0.0018)$ \\
capital & -0.1164 & -0.3812 & 0.4976 \\
& $(0.0085)$ & $(0.1497)$ & $(0.1499)$ \\
materials & 0.0018 & 0.0055 & -0.0073 \\
& $(0.0004)$ & $(0.0013)$ & $(0.0013)$ \\
\hline \hline
\end{tabular}

Table 3: Non-Price Elasticities

Mean values, std. errors in parenthesis

\begin{tabular}{ccccc}
\hline \hline & Labor & Capital & Materials & Cost \\
\hline Infrastructure & -0.0666 & 0.1632 & -0.1811 & -0.1609 \\
& $(0.0719)$ & $(0.0182)$ & $(0.1194)$ & $(0.1104)$ \\
Output & -0.2510 & 1.3934 & 1.1429 & 0.9420 \\
& $(0.1173)$ & $(0.0751)$ & $(0.2244)$ & $(0.2062)$ \\
Technology & 0.0032 & 0.0045 & 0.0047 & 0.0045 \\
& $(0.0001)$ & $(0.0019)$ & $(0.0009)$ & $(0.0008)$ \\
\hline \hline
\end{tabular}


Table 4: TFP Growth Decomposition

Annual growth rates in percentage

\begin{tabular}{cccccc}
\hline \hline Period & Observed TFP & Scale & Technology & Infrastructure & Factor Efficiency \\
\hline $1965-1996$ & 0.262 & 0.243 & -0.451 & 0.501 & -0.031 \\
$1965-1970$ & 0.316 & 1.070 & -0.571 & 0.179 & -0.362 \\
$1971-1975$ & 0.286 & 0.458 & -0.505 & 0.364 & -0.031 \\
$1976-1980$ & 0.525 & 0.276 & -0.448 & 0.679 & 0.018 \\
$1981-1985$ & 0.557 & -0.082 & -0.413 & 0.581 & 0.470 \\
$1986-1990$ & -0.374 & -0.079 & -0.385 & 0.578 & -0.488 \\
$1991-1996$ & 0.251 & -0.254 & -0.374 & 0.658 & 0.220 \\
\hline \hline
\end{tabular}

